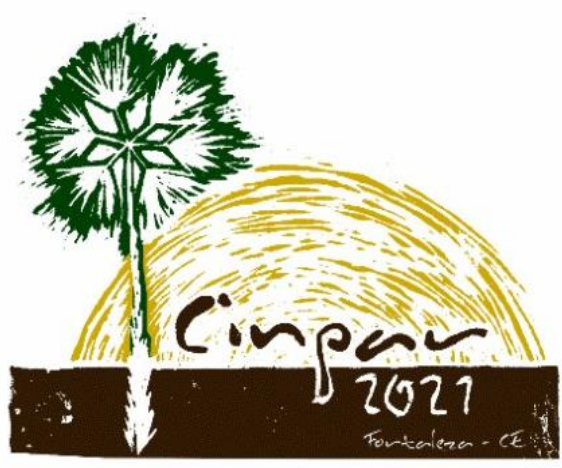

XVII Congresso Internacional sobre Patologia e

Reabilitação das Construções

XVII Congreso Internacional sobre Patología y Rehabilitación de las Construcciones

XVII International Conference on Pathology and Constructions Rehabilitation

FORTALEZA (Brasil), 3 a 5 de junho de 2021

https://doi.org/10.4322/CINPAR.2021.140

\title{
Patologia em fundações: Estudo de caso acerca do adensamento do solo nas laterais de uma edificação.
}

\section{Pathologies in foundations: Case study of soil density of the sides of a building.}

\author{
Gabrieli GUCKERT ${ }^{1}$, Adrieli Nunes SCHONS ${ }^{2}$ \\ ${ }^{1}$ Faculdade Estácio de Florianópolis, Florianópolis, Brasil, gg.guckertgabrieli@gmail.com \\ ${ }^{2}$ Centro Universitário Estácio de Sá Santa Catarina, São José, Brasil, adrielischons@gmail.com
}

\begin{abstract}
Resumo: O solo pode sofrer deformações por três principais motivos, sendo o enfoque desse trabalho a deformação por adensamento do solo. Nesse sentido, este artigo tem como objeto de estudo uma edificação pública no município de Balneário Camboriú/SC. Com base no exposto, o objetivo deste trabalho é discorrer de forma crítica e qualitativa sobre as medidas adotadas in loco para sanar a patologia oriunda de recalque diferencial e adensamento de solo, suas características e medidas de correção. Buscou-se verificar se as técnicas aplicadas na resolução dos problemas foram corretas e eficientes a longo prazo. Bem como, as implicações financeiras referentes a abordagem adotada, seja ela definitiva ou paliativa. Observamos, que as falhas construtivas e de projeto são as maiores responsáveis por problemas patológicos na maioria das construções. Os problemas relacionados a patologia em fundações, em suma, são causados por um ineficiente e incorreto estudo do solo ou na maior parte das vezes pela inexistência de tal estudo. Diante do exposto, a falta de informações sobre o projeto estrutural, estudo topográfico e execução da obra, tornaram inviável o estudo aprofundado da origem da patologia. Entretanto, com base nas inspeções visuais realizadas e a na revisão da literatura, concluiu-se que devido à idade avançada da edificação, se o adensamento de solo já não estiver estabilizado, ele é mínimo. Nesse sentido, a medida adotada foi eficaz e definitiva para quele ponto específico da edificação.
\end{abstract}

Palavras-chave: Patologia. Manifestações Patológicas. Recalque diferencial. Adensamento de Solo.

\begin{abstract}
The soil can suffer deformations for three main reasons, the focus of this work being the deformation due to the densification of the soil. In this sense, this article aims to study a public building at Balneário Camboriú / SC. Based on the above, the aim of this paper is to discuss critically and qualitatively the measures adopted in loco to solve the pathology problem resulted from differential settlement and soil density, its characteristics, and correction measures. We sought to verify whether the techniques applied to solve problems were correct and efficient in the long run. As well as the financial implications about the approach adopted, be it definitive or palliative. We observed that construction and design failures are the main responsible of pathological problems in most constructions. The problems related to pathology in foundations, in short, are caused by an inefficient and incorrect study of the soil or, usually, by the absence of such study. Given the above, the lack of information on the structural design, topographic study, and execution of the work made the in-depth study of the origin of the pathology impracticable. However, based on the visual inspections carried out and the literature review, it was concluded that due to the advanced age of the building, if the soil density is no longer stabilized, it is minimal. In this sense, the measure adopted was effective and definitive for that specific point of the building.
\end{abstract}


Keywords: Pathology. Pathological Manifestations. Differential settlement. Soil Densification.

\section{Introdução}

O termo patologia é comumente relacionado à medicina, sendo considerado a ciência que estuda as doenças, seus sintomas e causas. Já terapia pode ser considerada a ciência que estuda os meios para se curar e tratar doenças (OLINTO, 2001). Para a Engenharia Civil, patologia é uma disciplina que busca estudar as doenças que ocorrem nas estruturas e que com o tempo acarretam seu deterioramento. Sendo de extrema importância para aumentar a qualidade e durabilidade de edificações (NAZARIO e ZACAN, 2011).

Tendo em vista que as construções civis em suma se assentam sobre o solo, é de extrema importância conhecer o seu comportamento, principalmente quando solicitado este é solicitado por tensões. Um dos pontos mais importantes ao se estudar o solo é determinar as deformações oriundas de carregamentos verticais que tendem a provocar o recalque (deslocamento) da estrutura solo-fundação (PINTO, 2006).

A infraestrutura, mais comumente conhecida por fundação, têm por função transmitir os carregamentos provenientes da superestrutura para o solo. Seu comportamento pode ser afetado por diversos fatores a longo prazo. Começando pelo projeto, onde o solo deve ser estudado, passando pelas etapas construtivas e finalizando com os efeitos pós-implantação, na qual inclui sua degradação (MILITITSKY, SCHNAID e CONSOLI, 2015).

Quando o solo é submetido a carregamentos, ele tende a deformar, essa deformação recebe o nome de recalque. As deformações causadas por recalques movimentam a fundação e dependendo da intensidade dos deslocamentos, estes podem causar danos graves a superestrutura. Nesse sentido, o solo pode sofrer deformações por três principais motivos: deformação por escoamento lateral, deformação elástica e deformação por adensamento do solo (REBELLO, 2008).

A deformação dos solos por adensamento, variam de intensidade e duração em função do tipo de solo. Nesse sentido, os solos são classificados em função dos seus constituintes principais pelo trilinear dos solos. Para o caso dos solos areno-argilosos, estes são constituídos por cerca de $60 \%$ a $70 \%$ de areia e $30 \%$ a $40 \%$ de argila. Com base na curvas de tempo-recalque, sabe-se que a argila passa por três fases distintas de compreensão, sendo elas: compressão inicial, compressão primária e compressão secundária. (CAPUTO, 1988).

Ainda segundo Caputo (1988), a compressão inicial é instantânea, ocorre a partir do momento em o solo recebe o carregamento. A compressão primária ocorre nos primeiros anos da estrutura e apresenta valores de deformação maiores quando comparados com a compressão secundária, que por sua vez, não é tão significante devido a lentidão com que ocorre. $\mathrm{O}$ autor relata ainda, que não existe uma separação nítida entre as duas últimas fases, segundo ele, ambas coexistente em um certo momento.

$\mathrm{O}$ adensamento do solo pode ocorrer ainda por vibrações ocasionadas por tráfego intenso de veículos. Essas vibrações no solo tendem a compacta-lo, favorecendo recalques diferenciais que por consequência geram fissuras, trincas e rachaduras. $O$ recalque pode ser considerado estabilizado quando toda a água entre as partículas de solo é expulsa e o mesmo não apresenta mais variações de volume. Se não há danos a estrutura, a medida corretiva trata-se apenas de vedar a abertura (REBELLO, 2008).

Com base no exposto, analisaremos os problemas patológicos decorrentes do adensamento de solo em uma edificação pública localizada no município de Balneário Camboriú/SC. Para essa demanda, foi realizado um estudo acerca da patologia oriunda de recalque diferencial e adensamento de solo, suas características e medidas de correção.

Nesse sentido, o objetivo deste trabalho é discorrer de forma crítica e qualitativa sobre as medidas adotadas in loco para sanar a patologia encontrada na edificação. Buscamos verificar se as técnicas aplicadas na resolução dos problemas foram corretas e eficientes a longo prazo. Bem como, as implicações financeiras referentes a abordagem adotada, seja ela definitiva ou paliativa.

Patologia em fundações: Estudo de caso acerca do adensamento do solo nas laterais de uma edificação. 


\section{Manifestações Patológicas em Edificações}

No Brasil tem-se poucos dados sobre as causas dos problemas patológicos mais comumente encontrados nas construções. Contudo, por meio de estudos realizados por outros países, sabe-se que a causa principal é relacionada a movimentações dos materiais que compõem a estrutura e tensões oriundas de sobrecargas (THOMAZ, 1989).

Existem diversas manifestações patológicas que podem ocorrer nas estruturas de concreto armado e nos demais componentes da construção. Dentre as sintomatologias mais comuns estão: fissuras, deslocamentos, manchas, umidades, bolor e eflorescências. Grande parte das patologias coexistem e são causadas por um agente degradador previamente existente na edificação, dificultando encontrar a origem da patologia (BORGES, 2008).

\subsection{Patologia em Fundações}

O solo pode ser formado por decomposição química e desintegração mecânica da rocha de origem. Por meio da desintegração mecânica das rochas temos os pedregulhos e areias, considerados solos de partículas grossas. Temos também os siltes, considerados solos de partícula intermediárias e em condições muito especiais temos as argilas. Com relação à formação do solo por decomposição química, temos as rochas originadas por meio da modificação mineralógica da rocha de origem. Sendo representada pelas argilas, consideradas solos de partícula fina (CAPUTO, 1988).

Segundo Pinto (2006), essas deformações do solo podem ocorrer de forma rápida ou lenta dependendo do tipo de solo. Nos solos arenosos ou argilosos não saturados essa deformação ocorre de forma rápida, já nos solos argilosos saturados essa deformação é mais lenta, pois é necessário primeiramente a expulsão da água dos vazios presentes no solo. Esse processo de expulsão de água dos vazios do solo é denominado adensamento dos solos.

Quando os solos são submetidos a cargas que tendem a provocar deslocamentos na fundação, além do adensamento do solo ocorre outro fenômeno, chamado de recalque. Dependendo da intensidade dos deslocamentos, o recalque causado entre a estrutura solo-fundação pode causar danos sérios a superestrutura, comprometendo sua integridade (REBELLO, 2008).

Os recalques podem ser ocasionados por deformação elástica, deformação por escoamento lateral e deformação por adensamento. Além desses fatores, o recalque também pode ser causado por: escavação dos entornos da estrutura; tráfego intenso nos arredores da edificação e aumento do volume do solo (REBELLO, 2008).

Toda fundação recalca, pois, é característico do solo sofrer variação de volume quando sujeito a aplicação de cargas. Essas variações de volume tendem a provocar deslocamentos nos aparelhos de apoio. Uma fundação adequada deve apresentar fator de segurança e recalques compatíveis com o perfeito funcionamento da edificação (MILITITSKY, SCHNAID e CONSOLI, 2015).

Segundo Thomaz (1989), alguns fatores podem influenciar o aparecimento de recalques diferenciados, como, por exemplo: consolidação distinta do aterro carregado, bulbo de tensões entre fundações vizinhas, falta de homogeneidade do solo, rebaixamento do lençol freático, etc.

\subsection{Prevenção de patologias e recuperação de edifícios}

Thomaz (1989) relata em seu livro que, antes da execução das medidas de recuperação é necessário um diagnóstico aprofundado a respeito das causas da manifestação patológica. Esse diagnóstico deve considerar se patologia apresentou danos graves a segurança da estrutura. É importante que as medidas de recuperação se baseiem nas medidas preventivas, quanto maior essa aproximação maior será a eficiência alcançada com o reparo.

O projeto para reabilitar uma estrutura degradada é mais complexo do que o projeto para execução de uma nova construção. Isso se dá ao fato de que normalmente sabe-se muito pouco sobre uma estrutura existente e o processo de reabilitação para cada tipo de material é distinto (BERTOLINI, 2010).

Patologia em fundações: Estudo de caso acerca do adensamento do solo nas laterais de uma edificação. 
A prevenção de fissuras e demais patologias, em suma, necessitam de um bom planejamento, projeto e construção. $O$ custo do edifício não se restringe ao custo inicial de execução, os custos com manutenção também fazem parte desse cálculo. A não das patologias acabam interferindo diretamente em aumento de custos (THOMAZ, 1989).

\section{Metodologia}

A metodologia utilizada para a elaboração do trabalho, fundamenta-se em uma revisão bibliográfica sobre o tema procedida por um estudo de caso, cujo objetivo foi explorar a patologia ocasionado por adensamento de solo em uma edificação pública no município de Balneário Camboriú/SC. A seguir, apresentaremos o estudo de caso, isto é, o problema encontrado e as medidas tomadas in loco para sanar o problema.

Com base na revisão bibliográfica, serão analisadas as prováveis causas das patologias encontradas e analisaremos de forma qualitativa se as técnicas aplicadas na resolução da patologia foram corretas e eficientes a longo prazo (definitivas), ou se a abordagem foi paliativa. Bem como, suas implicações financeiras.

\section{Estudo de caso}

A construção objeto deste estudo de caso é um prédio público localizado no município de Balneário Camboriú/SC. A mesmo apresenta idade estimada em 55 anos e desempenha funções administrativas. Por se tratar de um prédio público se faz necessária uma breve explicação de como são executados os serviços na edificação.

Por licitação a empresa executora dos serviços se tornou responsável pelos serviços de engenharia nessa edificação, isso inclui desde pequenas manutenções até alterações de layout menos complexas. Entretanto, para que qualquer serviço possa ser realizado, a empresa precisa da autorização da engenharia responsável pelo órgão público.

Essa autorização é feita por meio da emissão de uma ordem de serviço. A ordem de serviços é composta por itens, esses itens são parte principal de um memorial descritivo, no qual constam todas as diretrizes de cuja empresa é obrigada a respeitar, como especificações técnicas, processo de execução, aplicação, acabamento, entre outros.

Além dos serviços a serem executados, a ordem de serviços contempla a importância financeira dos serviços e o prazo de execução. A empresa não pode realizar serviços diferentes do aprovado e não pode realizar serviço algum sem prévia autorização, primeiro sob risco de receber multa e ter que refazer os serviços sem ônus financeiro ao órgão público, segundo sob risco de não receber pelos serviços prestados.

Diante do exposto, os serviços autorizados consistiam na realização de pintura e execução da viga na lateral da edificação. Sendo o foco deste artigo o problema relacionado ao adensamento de solo, ou seja, patologia em fundações.

\subsection{Adensamento do solo}

Nas laterais da edificação foram encontradas aberturas entre a viga e o solo. Além de dar ao prédio uma aparência de abandono, a abertura causada pelo adensamento de solo estava favorecendo a entrada de roedores e demais bichos no subsolo do prédio.

Apesar de ser verificado em todo o perímetro da construção, essas aberturas foram mais perceptíveis na lateral do prédio onde não existe calçada, denominaremos "lateral A" (Figura 1). Na lateral supracitada o desnível com o solo era de aproximadamente $30 \mathrm{~cm}$ e apresentava uma extensão de 18,50 m. Enquanto na lateral oposta, denominada "lateral B" o desnível variava de $2 \mathrm{~cm}$ a $5 \mathrm{~cm}$.

Patologia em fundações: Estudo de caso acerca do adensamento do solo nas laterais de uma edificação. 




Figura 1 - Viga com desnível em relação ao solo

Fonte: Arquivo pessoal (2020).

Nas laterais onde existe calçada e o desnível apresentava uma abertura pouco significante, nenhum serviço foi realizado. Contudo, nas laterais onde o mesmo estava muito visível e com aberturas bem aparentes, serviços corretivos fizeram-se necessários.

Para melhor ilustrar o local de intervenção, foi elaborado o croqui abaixo (Figura 2). A parede lateral, no total, apresentava um comprimento de 18,50 m. A mesma estava subdividida em 5 partes, separa por pilares. Em cada trecho foram executadas uma nova viga e uma nova sapata.

Compete destacar, que o croqui é somente uma representação. Como não tivemos acesso ao projeto estrutural não foi possível representar de forma fiel à infraestrutura existente e suas dimensões. Contudo, as dimensões conhecidas referentes aos serviços executados para execução das novas vigas e sapatas foram representadas.

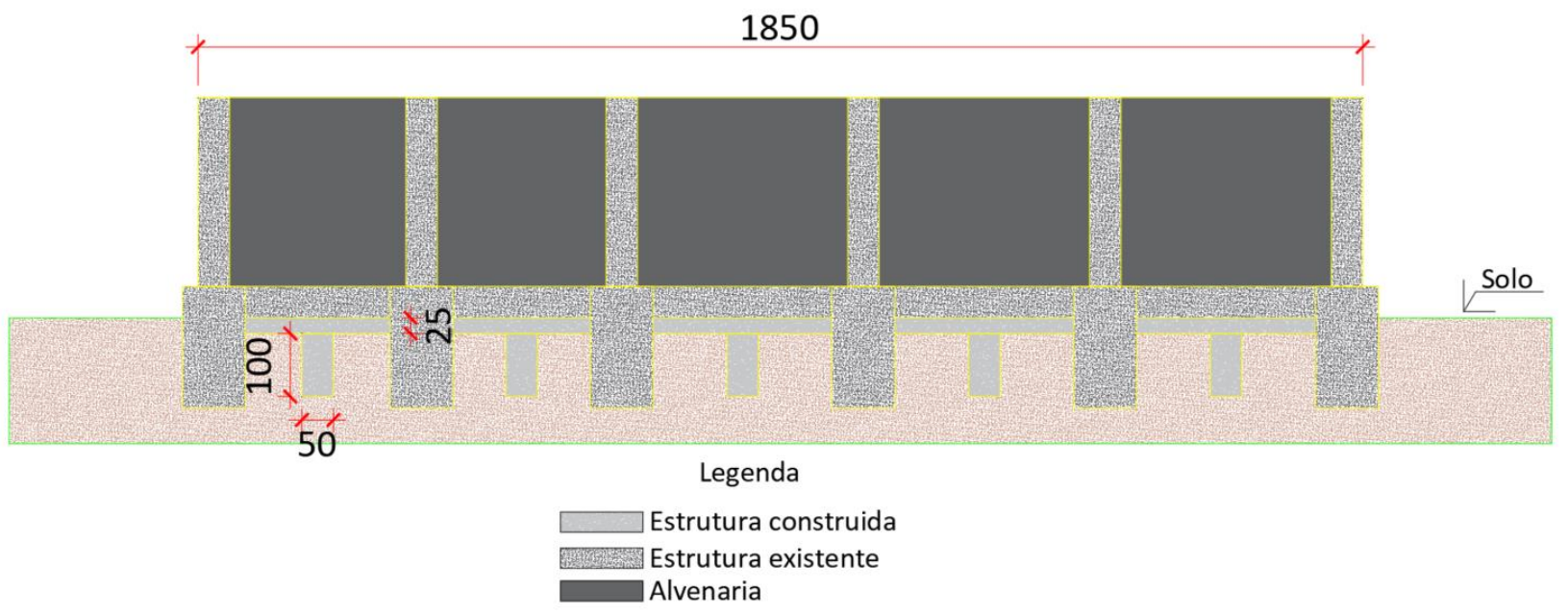

Figura 2 - Croqui: Local de intervenção e serviços executados

Fonte: Autor (2020).

Nesse sentido, os serviços corretivos realizados de modo a solucionar o problema na lateral mais crítica, "Lateral A", consistiram em realizar a escavação no local de forma a viabilizar a execução de 5 sapatas ( $50 \mathrm{x}$ $50 \times 100 \mathrm{~cm})$. Posteriormente em cada trecho, uma nova viga $(15 \times 25 \mathrm{~cm})$ foi construída logo abaixo da existente. Nas laterais a nova viga foi engastada nos pilares existentes (Figura 3 ) e por fim, cada nova viga foi encunhada na viga acima.

Patologia em fundações: Estudo de caso acerca do adensamento do solo nas laterais de uma edificação. 


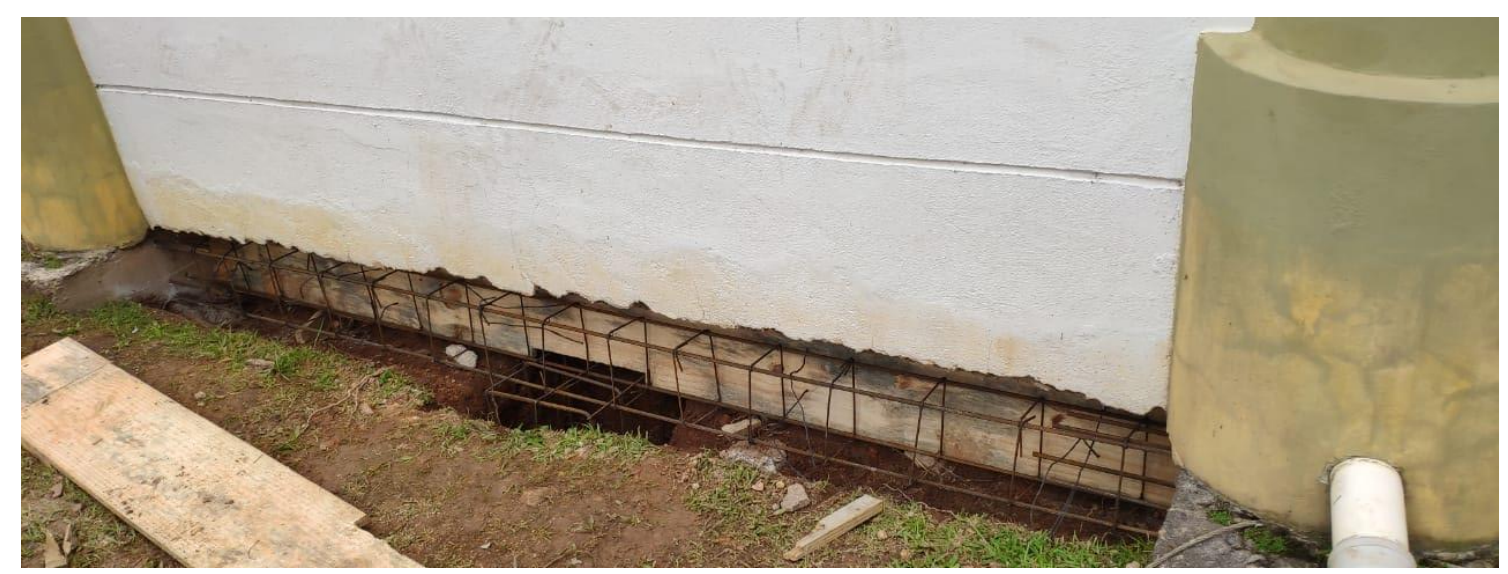

Figura 3 - Execução da sapata e da nova viga

Fonte: Arquivo pessoal (2020).

Segundo dados da CEPED (2015), o solo na região de Balneário Camboriú do tipo areno-argiloso e a litologia encontrada é granítica. Como não tivemos acesso ao relatório topográfico, não conseguimos identificar o nível de saturação do solo, ou seja, não conseguimos estimar a velocidade com que a deformação ocorreu. Todavia, sabemos que além do solo natural da região existe a presença de aterro na construção da edificação. Com base principalmente na inspeção visual e nos conhecimentos do profissional de engenharia, sabemos que o adensamento é sempre mais rápido no início da vida útil da edificação e que o mesmo tende a se estabilizar com o tempo. Nesse sentido, compete informar que a edificação estudada tem idade estimada em 55 anos.

Sabendo que o adensamento consiste na expulsão de água e ar dos vazios presentes no solo, esse fenômeno, bem como o recalque tende a se estabilizar com o tempo. Partindo do pressuposto que o adensamento está estabilizado, supõem-se que a medida tomada in loco será eficaz a longo prazo, pois a abertura não voltará a aparecer.

Contudo, outro fator deve ser considerado é que patologia em fundações não se restringe apenas a adensamento do solo ou recalque diferencial devido a isso. Vibrações devido a tráfego de veículos também tem impacto visível em qualquer estrutura não dimensionada a esse tipo de carregamento. Com relação às imediações da edificação, sabe-se que a mesma apresenta um fluxo intenso de carros e veículos pesados.

Diante do exposto, a estrutura dificilmente sofrerá sérias consequências futuras a respeito do adensamento de solo, pois devido a sua idade avançada, podemos concluir que se esses deslocamentos já não tiverem estabilizados, eles serão mínimos. Todavia, devido ao fluxo intenso de veículos leves e pesados na proximidade da construção, a mesma sofrerá com fissuras, trincas e rachaduras oriundas de vibrações do tráfego, que tendem a favorecer novos deslocamentos.

\section{Considerações Finais}

A técnica de diagnóstico adotada para corrigir o problema relacionado ao adensamento do solo na "Lateral $A^{\prime \prime}$ consistiu-se na inspeção visual da patologia encontrada in loco. Essa inspeção, considerou a experiência e conhecimentos do engenheiro responsável.

Falhas construtivas e de projeto serão sempre as maiores responsáveis por problemas patológicos em qualquer construção. Um projeto bem analisado, completo, que leva em torno todas as variáveis envolvidas será de grande importância para evitar a ocorrência de situações imprevistas cuja repercussão sobre qualidade e vida útil da edificação será sempre tão negativa. Outro ponto a ser considerado no estudo das causas mais comum de patologias, é a execução da obra. Não adianta tomar tanto cuidado e ser tão criterioso na elaboração de projetos completos e eficientes e não considerar a correta execução dos mesmos.

Os problemas relacionados a patologia em fundações, em suma, são causados por um eficiente e incorreto estudo do solo ou principalmente, pela inexistência desse estudo. Entretanto, a falta desse estudo

Patologia em fundações: Estudo de caso acerca do adensamento do solo nas laterais de uma edificação. 
topográfico, que no início sempre parece uma economia inocente, poderá acarretar patologias que podem interferir na durabilidade e estabilidade da edificação. Além de deixar a edificação visualmente desagradável.

Compete destacar, que não temos informações suficientes acerca dos projetos e da execução do prédio para afirmar o que causou os problemas patológicos encontrados. Nesse sentido, as considerações foram oriundas do estudo da bibliografia e não podem ser replicadas com certeza a essa edificação, pois não temos informações a respeito de projeto e execução da mesma para fazer tais afirmações. Contudo, sabemos que essas patologias existem, que poderiam ter sido evitadas e que as informações expressas acima são, pela bibliografia, as causas mais comuns desse problema.

A viga construída na lateral da edificação para solucionar os problemas causados pelo adensamento do solo, é uma solução definitiva para aquela ponto específico de construção. Conforme relatado, esse problema está presente em todo o perímetro do prédio, contudo os serviços corretivos foram realizados somente no ponto mais crítico, correspondendo a cerca de $7 \%$ da totalidade da edificação. Acredita-se que devido à idade da construção o adensamento já está estabilizado, então essa abertura não vai voltar a aparecer no local de intervenção, bem como, não aumentará de proporção nas laterais restantes da construção.

Todavia, não foi realizado um estudo do solo para saber se essa estabilização de fato ocorreu ou não, estamos tomando como base a idade estimada da edificação, que é de aproximadamente 55 anos. Tendo em vista que o problema do adensamento do solo não afeta somente as laterais do prédio, se o solo não se estabilizou os recalques diferenciais causados por esse agente continuarão ocorrendo, e as fissuras características desse evento voltarão a aparecer com o passar do tempo, a longo prazo os sintomas típicos dessa patologia nos mostrarão se o problema de fato foi solucionado.

Por tanto, os serviços executados para tratar o problema decorrente do adensamento do solo, foram definitivos para quele ponto em específico da edificação e apresentaram uma importância financeira de aproximadamente $\mathrm{R} \$ 7.150,00$ (sete mil cento e cinquenta reais). Replicando esses mesmos serviços para as demais laterais do prédio, temos um valor estimado em $\mathrm{R} \$ 103.900,00$ (cento e três mil e novecentos reais). Contudo, nessa estimativa não está considerando os serviços para demolição e execução da calçada nas laterais onde se faz necessário. Tendo em vista que o prédio tem um perímetro de cerca de 290 metros, a importância financeira real seria muito maior.

Principalmente devido ao vulto financeiro e a necessidade de intervenções na totalidade da edificação, a administração pública responsável pela edificação contrataria os serviços através de processos licitatórios específico. Contudo, dependendo do tempo que a levar para ser realizada uma reforma global na edificação, é provável que essa ideia seja deixada de lado, e uma nova estrutura seja construída para migrar os serviços da edificação antiga para a nova.

Sabendo que pouco se estuda sobre patologias no Brasil comparado a países mais desenvolvido, se torna difícil analisar as causas patológicas que afetam edificações mesmo que com todas as informações sobre sua execução. Sem informação alguma se torna ainda mais complicado, justificando a execução de serviços paliativos na maior parte dos casos.

Por tanto, podemos concluir que os serviços executados foram eficazes e eficientes para aquele ponto específico. Se o adensamento do solo já estiver estabilizado, o que pela idade da edificação, acredita-se que sim, esses deslocamentos não voltarão a ocorrer. Contudo, as fissuras, trincas e rachaduras continuarão aparecendo, dessa vez causadas por vibrações no solo devido ao tráfego intenso na proximidade da construção. Para esses sintomas patológicos, um estudo específico e detalhado deverá ser feito, haja visto que este não foi o enfoque do presente trabalho.

Podemos perceber também, que a prevenção é, e sempre será, a alternativa financeira mais viável, principalmente porque os custos com manutenção afetarão os demais custos da edificação em toda sua vida útil, mesmo que por muitas vezes isso não seja considerado.

\section{Agradecimentos}

Agradeço primeiramente a Deus, pois na fé sempre encontrei forças para conquistar meus objetivos e vencer minhas dificuldades. Aos meus pais, cujo exemplo de vida me tornou a pessoa que sou. Ao meu noivo, por

Patologia em fundações: Estudo de caso acerca do adensamento do solo nas laterais de uma edificação. 
todo apoio e paciência nessa jornada. Aos meus professores, grandes mestres que me transmitiram conhecimento, pessoas nas quais me espelho. Por fim, agradeço a todas as pessoas que me auxiliaram na elaboração desse trabalho.

\section{Referências Bibliográficas}

BERTOLINI, L. Materiais de Construção: patologia, reabilitação, prevenção. Tradução de Leda BECK. São Paulo: Oficina de Textos, 2010. 313 - p.

BORGES, G. M. Manifestações patológicas incidentes em reservatórios de água elevados executados em concreto armado. Feira de Santana: Universidade Estadual de Feira de Santana, 2008. 7-8 p. Monografia (Graduação).

CAPUTO, H. P. Mecânica dos Solos e suas aplicações (fundamentos). 6o. ed. Rio de Janeiro: LTC - Livros técnicos e Científicos Editora S.A, v. 1, 1988. 14;33;103;106 p.

CEPED, UFSC. Análise de vulnerabilidade a desastre do Município de Balneário Camboriú. Florianópolis: CEPED UFSC, 2015. 35, 72, 93 p.

MILITITSKY, J.; SCHNAID, F.; CONSOLI, N. C. Patologia das fundações. 2o. ed. São Paulo: Oficina de textos, 2015.

NAZARIO, D.; ZACAN, E. C. Manifestações das patologias construtivas nas edificações públicas da rede municipal de Criciúma: inspeção dos sete postos de saúde. Criciúma: Universidade do extremo Sul Catarinense (UNESC)., 2011. 2 p. Artigo (Graduação).

OLINTO, A. Minidicionário Antônio Olinto da língua portuguesa. 2o ed. rev. e ampl. ed. São Paulo: Moderna, 2001. 390 - 535 p.

PINTO, C. D. S. Curso básico de mecânica dos solos em 16 aulas. 3‥ ed. São Paulo: Oficina de textos, 2006.

REBELLO, Y. C. P. Fundações: guia prático de projeto, execução e dimensionamento. São Paulo: Zigurate Editora, 2008.

THOMAZ, E. Trincas em edifícios: causas, prevenção, e recuperação. ( 3. tiragem 1998). ed. São Paulo: PINI: Instituto de Pesquisas Tecnológicas, 1989. 19-25, 45,83, 94-102,159 p.

Patologia em fundações: Estudo de caso acerca do adensamento do solo nas laterais de uma edificação. 